\title{
1 TAXONOMIC BIAS AND TRAITS OF THE GLOBAL AMPHIBIAN PET-TRADE
}

2

3 Nitya Prakash Mohanty ${ }^{1,2}$, John Measey ${ }^{1}$

4

$5{ }^{1}$ Centre for Invasion Biology, Department of Botany \& Zoology, Stellenbosch University,

6 South Africa 7602.

$7 \quad{ }^{2}$ Andaman Nicobar Environment Team, Wandoor, South Andaman, Andaman and Nicobar

8 Islands 744103.

9

10 Corresponding Author: Nitya Prakash Mohanty, nitya.mohanty@gmail.com

11

$12 \underline{0000-0001-7768-6483}$

$13 \quad \underline{0000-0001-9939-7615}$

14 


\section{Abstract}

16 The pet-trade is recognized as the major pathway for amphibian introductions worldwide,

17 yet our understanding of the trade is limited. In this study, we systematically assess

18 amphibian species in the pet-trade, i) characterising taxonomic bias and ii) evaluating

19 species-traits as predictors of traded species and trade volume. We collated a global list of

20443 traded amphibians and a regional dataset on trade volume. Species-traits (body size,

21 native range size, clutch size, and breeding type) and conservation status, were considered

22 as predictors of traded species and volume. We found a strong bias for certain Families,

23 along with a preference for large-bodied and widely distributed species with a larval phase,

24 in the pet-trade. However, species-traits performed poorly in predicting trade volume of pet

25 amphibians in the USA. The identified species-traits and taxonomic bias of the trade is used

26 to predict species likely to be traded as pets in the future.

27 Keywords: Amphibia; invasive species; trade; life-history traits

Introduction

29 Trade in live amphibians has increased drastically over the last few decades [1]; trade for

30 pets in particular is responsible for the majority of amphibian introductions beyond their

31 native range [2]. Van Wilgen and colleagues [3] recently recorded 263 species of amphibians

32 with extra-limital populations, including those in trade, captivity or with non-established

33 populations. Current patterns of invasions are driven by historic introductions ('invasion

34 debt'; [4]), and thus current trade will likely influence future invasions. Current lists of

35 extralimital species [3] suggest that future invasions will encompass a broader taxonomic

36 diversity than is currently known [5]. Therefore, it is essential to understand characteristics

37 of species in the pet-trade and its taxonomic biases. 
39 The amphibian pet-trade has recently received attention from studies aiming to,

40 characterise trade regionally $[6,7]$ and internationally $[8,9,10]$, and to inform risk

41 assessments [11]. However, the amphibian pet-trade still remains poorly understood.

42 Regional trade data is available only for a limited set of countries [8,12]. Geographically, pet

43 ownership and trade in Asia is understudied [13,14]. Research is also taxonomically biased,

44 with trade in species listed by the Convention on International Trade in Endangered Species

45 of Wild Fauna and Flora (CITES) being relatively well documented, even though other

46 species may account for a much larger component of international trade [1].

48 Given that trade is dynamic and new species enter the trade frequently [1,6], it is essential

49 to move beyond currently traded species and understand which species are likely to be

50 traded in the future. Broad-scale predictors of traded species, such as life-history traits have

51 been used to understand pet-trade dynamics (e.g. reptiles [15]; birds [16,17]). Species-traits associated with characteristics of the amphibian pet-trade (species traded and trade

53 volume) have not yet been assessed, although release of amphibian pets is known to be

54 influenced by life-history traits and economic parameters [18].

56 The amphibian pet-trade has emerged as a subject of conservation importance from the

57 viewpoint of invasions, overexploitation, and diseases [10]. Yet, systematic assessments of

58 the pet-trade seldom test its predictors (but see [18]). In this study, we aim to characterize

59 amphibian species in the pet-trade. Specifically, i) we characterise taxonomic bias in traded

60 species and ii) evaluate life-history traits as predictors of traded species and trade volume.

\section{Methods}


63 We collated a list of traded amphibians based on a literature review (Supplementary

64 Information 1) and supplemented it with the United States Fish and Wildlife Service's Law

65 Enforcement and Management Information System (LEMIS) data on live imported

66 amphibians into the USA from 2013 to 2018. Based on the 'purpose' variable associated

67 with the imports, we considered only 'commercial', 'breeding in captivity' and 'personal'

68 categories as those pertaining to the pet-trade. Since our interest was in species-level traits

69 as predictors, only import records with identified species were retained, discarding taxa

70 identified up to genus-level and unspecific categorization such as 'non-CITES'. We corrected

71 for taxonomy based on Frost [19] and assigned an Order, Superfamily, and Family to each

72 species. Volume of trade is rarely recorded and LEMIS data for the USA provides a unique

73 opportunity to make further inferences about trade (e.g. [12]), especially on species'

74 popularity in the pet-trade. The total number of individuals imported for each species into

75 the USA from 2013 to 2018 served as a measure of 'trade volume'.

77 Species-traits for amphibians were collated mainly from the AmphiBIO database [20]. This was further supplemented by data from Allen et al. [21] and AmphibiaWeb

79 (https://amphibiaweb.org/). We selected traits with data available for a majority of species,

80 which were likely to influence pet ownership and trade. Range size may influence availability

81 for trade [22] and therefore data on native range and global range (i.e. including non-native

82 range) was obtained by geoprocessing polygons from the IUCN spatial database [23]. Body

83 size is likely to determine the suitability of species for the pet-trade [24]; extremely small or

84 large body sizes may be avoided due to reduced detection and increased costs of housing,

85 respectively [18]. Clutch size and breeding mode (direct developing, larval, or viviparous)

86 have direct bearing on the ease of captive breeding. 
88 Trade status of species, as recorded by CITES, and conservation status according to the

89 International Union for Conservation of Nature's (IUCN) Red List were also considered, as

90 these variables could influence trade volume [17]. Each species was assigned a CITES

91 Appendix (I, II, III) or recorded as 'non-listed'; following Vall-Ilosera \& Cassey [17], IUCN

92 'Near-threatened' and 'Least Concern' species were categorized as 'non-threatened', and

93 the rest as 'threatened', while treating 'Data Deficient' as a category of its own. Data on all

94 chosen predictors were available for a sizable number of amphibians for trade status ( $\mathrm{n}=$

$951388)$ and trade volume analyses $(n=173)$. We did not include some potentially relevant

96 traits (climate, diet, longevity, offspring size) as too few species are scored in the AmphiBIO

97 database.

\section{Data Analyses}

To evaluate taxonomic bias in representation of amphibian Orders, Superfamilies or Families

101 in traded species, number of species at each taxonomic level was compared with the total number of known amphibian species [19], with respect to a random expectation generated using the hypergeometric distribution (see [3]). Taxa outside the $95 \%$ confidence intervals were deemed either over- or under-represented in our sample of traded species. To assess the predictors of traded species and trade volume, we constructed a mixed-effects logistic regression model in the Ime4 package [25]. Prior to the analyses, data on both body size,

107 clutch size, and range sizes (native and global range) were log-transformed. We controlled

108 for potential taxonomic dependence by using 'Family' as a random effect in our analysis on traded species and 'Superfamily' for trade volume. We did not include 'CITES' status as a 
111 on the Akaike Information Criterion (AIC), supplemented by a measure of model fit ( $\mathrm{R}^{2}{ }_{\mathrm{GLMM}}$;

112 [26]). Based on the parameter estimates of the best model, 'trade scores' (likelihood to be

113 traded) were computed for all species and scaled for comparison. All statistical analyses

114 were carried out in $\mathrm{R}$ (version 3.5 .3 ; [27]), whereas, spatial computations were executed in

115 ArcMap (version 10.6.1; [28])

\section{Results}

118 i) Taxonomic bias

119 Our literature review and US import records resulted in a total of 443 uniquely identifiable 120 species in the amphibian pet-trade from 1971 to 2018 (Supplementary Information 1). Frogs

121 (Order Anura) constituted the majority of the traded species ( $n=262)$, followed by salamanders (Caudata $=47$ ) and caecilians (Gymnophiona $=3$ ). An analysis accounting for all

123 extant taxa revealed a taxonomic bias in traded amphibians, with over- and

124 underrepresented taxa at Order, Superfamily, and Family level (Fig. 1). At the Order level,

125 Caudata were over-represented in traded taxa, whereas Anuran and Gymnophiona were

126 under-represented (Fig. 1a). Traded species were also biased towards the Superfamilies

127 Salamandoidea, Pipoidea, Dendrobatoidea, and Discoglossoidea (Fig. 1b). The Families

128 Dendrobatidae, Mantellidae, Hyperoliidae, Pipidae, Ambystomatidae, and Salamandridae

129 contributed disproportionately high species to the trade (Fig. 1C).

130 ii) Predictors of traded species and trade volume

131 Of the 15 candidate models built to predict traded species, the global model performed the

132 best (Table 1). However, only body size, range size, and breeding type had significant

133 effects, with the likelihood for species to be traded being positively influenced by body size

$134(\beta=1.06, \mathrm{SE}=0.19, p<0.001)$, range size $(\beta=0.38, \mathrm{SE}=0.05, p<0.001)$, and a 'larval' 
135 breeding type $(\beta=1.34, \mathrm{SE}=0.50, p=0.007)$. The best model explained $59 \%$ of the variation

136 overall (including the random effect of Family); on their own the predicting traits explained

$13741 \%$ of the variation (Table 1). Native range size and global range size did not differ in their

138 explanatory ability. Based on their 'trade scores' (output of the best model), we produced a

139 list of 20 species likely to be traded in the future (Table 2).

141 The USA imported at least 3,655,620 live amphibians for the pet-trade, belonging to 283

142 species, between 2013 to 2018 (Supplementary Information 2). Three models were selected

$143(\triangle \mathrm{AIC}<2)$ to explain trade volume, with predictors breeding mode, $\mathrm{CITES}$, and IUCN status.

144 However, these predictors explained only $1.5 \%$ of the variation in trade volume

145 (Supplementary Information 2).

\section{Discussion}

148 In this study, we collate a comprehensive list of amphibian species in the global pet-trade.

149 We find a strong bias for certain Families, along with a preference for large-bodied and

150 widely distributed species with a larval phase, best characterise the global trade in

151 amphibians. Our analyses reveal that a few amphibian Families, with high species diversity

152 (e.g. Mantellidae, Dendrobatidae, Hyperoliidae, Salamandridae), contribute

153 disproportionately to the trade. Species within a Family are likely to have broadly similar

154 traits that make them candidates for the pet-trade [17]. Along with this taxonomic bias, the

155 identified species-traits can predict new species likely to enter the trade. Our example list of

156 species based on predictions of trait-based models (Table 2) suggests that future traded

157 species are likely to be from already overrepresented Families (e.g. Dendrobatidae). 
159 The modelling results indicate that traded species are associated with species-trait

160 preference (e.g. large body size), human sampling effort (e.g. large range size), and

161 husbandry practices (e.g. indirect development). Body size is known to be positively

162 associated with intentional introduction of amphibians [22]. This result is unsurprising as

163 most intentional introductions are through the pet-trade [2] and large bodied-species are

164 more likely to be released [18]. Although large body size does not lead to higher success of

165 establishment or spread [21], it is predictive of greater impact in invasive amphibians [29].

166 Tingley et al.[22] noted the influence of large range size on introduction probability and

167 attributed it to increased opportunities for sampling by humans. Additionally, we posit that

168 a larger range is also likely to include more countries, which may increase the chances of a

169 species' trade being facilitated, overcoming regulatory restrictions. Species with larval

170 offspring are likely to be cheaper to raise as compared to direct developing species.

171 Thereafter, most captive bred pet amphibians are imported as sub-adults (e.g. [12]). The

172 minimal effect of conservation status ('IUCN') on pet-trade of species has been previously

173 documented with birds [17].

175 The species-traits considered in our analyses performed poorly in predicting trade volume of

176 pet amphibians in the USA. Human aspects of the trade, such as availability of skills for

177 captive breeding, exemption from regulations, and economics of scale are likely to drive

178 trade, particularly volume (see [17] for a detailed discussion). Species attributes not

179 considered in our analyses, such as colour, ornamentation, rarity, and perceived cost of

180 ownership $[15,30]$, may also account for unexplained variation in traded species and their

181 volume. However, information on these traits are not readily available for many amphibian 
species. Amphibian trait data also suffers from incompleteness, limiting the number of species that can be considered [20,21].

185 Recent studies have attempted to understand pet ownership and stakeholder perception of

186 pet-trade management [14,31]. Future research must systematically assess human

motivations for pet ownership and release, preferences for traits to better hone predictions

188 of which species are likely to be traded, and better inform risk assessments.

\section{Acknowledgements}

191 We would like to thank the USFWS for sharing data on amphibian imports; Martin

192 Schlaepfer, Oliver Stringham, Hollis Dahn, James Baxter-Gilbert and Carla Wagener for

193 valuable inputs to the study.

\section{Author contributions}

195 N.P.M. and J.M. conceived the study. N.P.M. collated and analysed the data. N.P.M. and

196 J.M. wrote the manuscript and approved the final version of the manuscript.

197 Accessibility

198 All data associated with the manuscript are uploaded as part of electronic supplementary

199 material, S3.

\section{Funding}

201 This research was supported by the DST-NRF Centre of Excellence for Invasion Biology (CIB).

\section{Competing interests}

203 The authors declare no competing interests.

\section{Ethical statement}

205 No ethical approval was required for this study. 


\section{References}

207 1. Carpenter, A. I., Andreone, F., Moore, R. D., \& Griffiths, R. A. (2014). A review of 208 the international trade in amphibians: the types, levels and dynamics of trade in 209 CITES-listed species. Oryx, 48(4), 565-574.

2. Kraus, F. (2009). Alien reptiles and amphibians: a scientific compendium and analysis (Vol. 4). Springer Science \& Business Media. taxonomically and geographically constrained information base limits non-native reptile and amphibian risk assessment: a systematic review. PeerJ, 6, e5850.

4. Essl, F., Dullinger, S., Rabitsch, W., Hulme, P.E., Hülber, K., Jarošík, V., Kleinbauer, 203-207.

5. Capinha, C., Seebens, H., Cassey, P., García-Díaz, P., Lenzner, B., Mang, T., Moser, and the global flows of alien amphibians and reptiles. Diversity and and amphibians within the United Kingdom over a ten-year period. Herpetological Journal, 21, 27-34. amphibians and reptiles from Indonesian New Guinea. Biodiversity Conservation, 
229 8. Herrel, A., \& van der Meijden, A. (2014). An analysis of the live reptile and amphibian trade in the USA compared to the global trade in endangered species. The Herpetological Journal, 24(2), 103-110.

9. Auliya, M., García-Moreno, J., Schmidt, B. R., Schmeller, D. S., Hoogmoed, M. S., Fisher, M. C., et al. (2016). The global amphibian trade flows through Europe: the need for enforcing and improving legislation. Biodiversity Conservation, 25, 2581-2595. doi: 10.1007/s10531-016-1193-8

10. Pasmans, F., Bogaerts, S., Cunningham, A.A., Braeckman, J., Hellebuyck, T., Griffiths, R.A., Sparreboom, M., Schmidt, B.R. and Martel, A. (2017). Future of keeping pet reptiles and amphibians: towards integrating animal welfare, human health and environmental sustainability. Veterinary Record, 181(7). invasiveness of the selected exotic amphibians from pet trade in the European Union. Journal for Nature Conservation, 31, 22-28. trade in live Xenopus laevis imported into the USA. Salamandra, 53, 398-404. Wogan, G.O. \& Phimmachak, S. (2016). Estimating the global trade in Southeast Asian newts. Biological Conservation, 199, pp.96-100. 
251 15. van Wilgen, N. J., Wilson, J. R. U., Elith, J., Wintle, B. A., \& Richardson, D. M. (2010). Alien invaders and reptile traders: What drives the live animal trade in South Africa? Animal Conservation, 13, 24-32. composition and characteristics of the Taiwanese bird trade. Biological Invasions, 16(12), 2563-2575.

17. Vall-llosera, M., \& Cassey, P. (2017). Physical attractiveness, constraints to the trade and handling requirements drive the variation in species availability in the Australian cagebird trade. Ecological Economics, 131, 407-413. factors that influence the release of alien reptiles and amphibians by pet owners. Journal of Applied Ecology, 55(6), 2632-2640.

19. Frost, D. R. (2019). Amphibian Species of the World: An Online Reference. Version 6.0. New York, NY: American Museum of Natural History. Available online at: http://research.amnh.org/herpetology/amphibia/index.html (2017). AmphiBIO, a global database for amphibian ecological traits. Scientific Data, 4,170123. (2010). The frog filter: amphibian introduction bias driven by taxonomy, body size and biogeography. Global Ecology and Biogeography, 19(4), 496-503. 
274 23. IUCN Red List of Threatened Species (2019). https://www.iucnredlist.org. Downloaded on 9th April 2019. 28-36.

25. Bates, D., Mächler, M., Bolker, B., \& Walker, S. (2015). Fitting Linear MixedEffects Models Using Ime4. Journal of Statistical Software, 67(i01). R2 from generalized linear mixed-effects models. Methods in Ecology and Evolution, 4(2), 133-142.

27. $R$ Core Team (2019). R: A language and environment for statistical computing. $R$ Foundation for Statistical Computing, Vienna, Austria. URL https://www.Rproject.org/.

28. Environmental Systems Research Institute (ESRI) (2012). Arc-GIS Release 10.6.1. Redlands, CA.

29. Measey, G. J., Vimercati, G., Villiers, F. A., Mokhatla, M., Davies, S. J., Thorp, C. J., \& Kumschick, S. (2016). A global assessment of alien amphibian impacts in a formal framework. Diversity and Distributions, 22, 970-981. the harvest of wild populations within a species. Ecological Economics, 93, 278283. 
298 Figure 1. Taxonomic patterns in amphibian (A) Orders, (B) Superfamilies, and (C) Families

299 present in the global amphibian pet-trade. The median (green line) and 95\% confidence

300 intervals (brown lines above and below), adjusted for multiple comparisons, were estimated

301 from the hypergeometric distribution. The points that fall between the $95 \%$ confidence

302 intervals are not significantly over or under-represented, relative to the number of

303 amphibian species worldwide. Those labelled taxa that fall above the $95 \%$ confidence

304 intervals are over-represented and those below are under-represented in our sample of

305 traded amphibians.

306

307 
308 Table 1. Generalized linear mixed-effects models predicting amphibian species in the pet-

309 trade with predictors body size, native range size $\left(\mathrm{km}^{2}\right)$, breeding mode (LA - larval, VV -

310 viviparous, DD - direct developing), and clutch size. Models run with 'Family' as a random

311 effect. $\triangle \mathrm{AIC}$ is the difference in Akaike information criterion values (AIC) between the

312 current model and the best and weight (Akaike weight) is the relative support a model has

313 from the data compared to the other models in the set. Marginal $\left(R_{m}^{2}\right)$ and conditional

$314\left(R_{c}^{2}\right) R_{\text {GLMM }}^{2}$ are reported for each model and provide an estimate of the explained variance.

\begin{tabular}{ccccc}
\hline Model & $\Delta$ AIC & Weight & $\boldsymbol{R}^{2}{ }_{\boldsymbol{m}}$ & $\boldsymbol{R}^{2}{ }_{\boldsymbol{c}}$ \\
\hline Size + Range + Breeding + Clutch + IUCN & 0.00 & 0.83 & 0.41 & 0.59 \\
Size + Range + Breeding & 3.61 & 0.14 & 0.41 & 0.59 \\
Size + Range + Clutch & 7.13 & 0.02 & 0.36 & 0.57 \\
Size + Range + IUCN & 10.00 & 0.01 & 0.34 & 0.57 \\
Size + Range & 12.83 & 0.00 & 0.34 & 0.57 \\
Range + Breeding & 54.54 & 0.00 & 0.36 & 0.51 \\
Range + IUCN & 59.52 & 0.00 & 0.28 & 0.48 \\
Range & 66.62 & 0.00 & 0.28 & 0.47 \\
Size + Breeding & 106.69 & 0.00 & 0.26 & 0.51 \\
Breeding + Clutch & 127.67 & 0.00 & 0.25 & 0.46 \\
Size & 127.67 & 0.00 & 0.19 & 0.51 \\
Clutch & 135.05 & 0.00 & 0.17 & 0.42 \\
Breeding & 194.60 & 0.00 & 0.13 & 0.32 \\
IUCN & 197.97 & 0.00 & 0.06 & 0.29 \\
Null & 226.99 & 0.00 & 0.00 & 0.27 \\
\hline & & &
\end{tabular}


317 Table 2. List of example amphibian species that are likely to be traded as pets in the future,

318 based on parameter estimates ('trade score') of the selected species-trait based model, with

319 associated body size $(\mathrm{mm})$, native range size $\left(\mathrm{km}^{2}\right)$, and breeding mode (LA - larval). 'Trade

320 score' is standardized (from 0 to 1 ) to enable comparisons of candidate species for the pet-

321 trade.

\begin{tabular}{|c|c|c|c|c|c|}
\hline Species & Family & Body & Range & Breeding & Trade Score \\
\hline Ameerega flavopicta & Dendrobatidae & 30.5 & 932405 & LA & 0.89 \\
\hline Amphiuma means & Amphiumidae & 1162 & 578601.6 & LA & 0.85 \\
\hline Adelphobates quinquevittatus & Dendrobatidae & 17.3 & 1453408 & LA & 0.84 \\
\hline Andrias japonicus & Cryptobranchidae & 1360 & 69446.11 & LA & 0.83 \\
\hline Lissotriton helveticus & Salamandridae & 95 & 1642151 & LA & 0.83 \\
\hline Anaxyrus woodhousii & Bufonidae & 127 & 4135562 & LA & 0.82 \\
\hline Gyrinophilus porphyriticus & Plethodontidae & 232 & 1007390 & LA & 0.82 \\
\hline Rhinella icterica & Bufonidae & 190 & 1664952 & LA & 0.82 \\
\hline Anaxyrus boreas & Bufonidae & 125 & 4253188 & LA & 0.82 \\
\hline Pseudotriton montanus & Plethodontidae & 207 & 919587 & LA & 0.82 \\
\hline Polypedates maculatus & Rhacophoridae & 83 & 2937058 & LA & 0.81 \\
\hline Aglyptodactylus madagascariensis & Mantellidae & 92 & 117540.7 & LA & 0.81 \\
\hline Ameerega braccata & Dendrobatidae & 21.8 & 290834.5 & LA & 0.81 \\
\hline Ameerega petersi & Dendrobatidae & 31 & 91707.26 & LA & 0.80 \\
\hline Hyloxalus bocagei & Dendrobatidae & 29.5 & 57125.89 & LA & 0.80 \\
\hline Chioglossa lusitanica & Salamandridae & 160 & 73377.19 & LA & 0.80 \\
\hline Hyloxalus elachyhistus & Dendrobatidae & 25.7 & 14835.79 & LA & 0.79 \\
\hline Boophis doulioti & Mantellidae & 52.4 & 261000 & LA & 0.79 \\
\hline Ambystoma macrodactylum & Ambystomatidae & 248 & 2240399 & LA & 0.79 \\
\hline Xenopus muelleri & Pipidae & 90 & 3408269 & LA & 0.78 \\
\hline
\end{tabular}


